ARQUITEXTOS

ISSN 1819-2939/ ISSNe 2706-8099

Año 26, No 34, enero-diciembre de 2019

pp. $97-108$

\title{
Las canchas de fútbol en Morelos, México: un espacio de socialización para las "futboleras"*
}

The soccer fields in Morelos, Mexico: a socialization space for "futboleras"

Tania Alejandra Ramírez**

INAH, Centro Regional Morelos

Recibido: 8 de octubre de 2019

Aceptado: 4 de noviembre de 2019

\section{RESUMEN}

Las canchas de fútbol privadas y las ligas femeniles de fútbol no profesional son lugares que las mujeres han peleado para poder construir espacios de autocuidado, diversión, convivencia y socialización. La liga contiene un sentido metafórico, ya que hilvana diversos aspectos de sus vidas mediante la experiencia del "gusto" por el soccer.

Palabras clave: género, deporte, fútbol femenil, procesos de socialización, “futboleras”.

\section{ABSTRACT}

Private football pitches and non-professional women's football leagues are places that women have fought for, to be able to build spaces of self-care, fun, and socialization. The league contains a metaphorical sense as it relates various aspects of their lives through the experience of "passion" for soccer.

Keywords: Gender, sports, women's soccer, socialization processes, "futboleras".

\footnotetext{
* Antecedentes del documento. La investigación es producto de la tesis desarrollada en la Maestría en antropología social. Se analizó el cómo las canchas de soccer son un espacio no solo para jugar o ver jugar soccer, sino desplegar diversas formas de sexualizar y reconstruir la performatividad del género. (Nota del editor: se han respetado en el artículo las expresiones utilizadas por la autora, entre ellas, regionalismos y vocablos con nuevos significados)

** Tania Alejandra Ramírez Rocha. Maestra en antropología social por el Centro de Investigaciones y Estudios Superiores en Antropología Social (CIESAS, CDMX). Profesora investigadora del Instituto Nacional de Antropología e Historia (INAH, Centro Regional Morelos, México).
} 


\section{Introducción}

Abordo la experiencia deportiva de trece mujeres que forman parte de una liga de fútbol soccer no profesional, en el estado de Morelos, México. Las canchas donde juegan son un espacio de socialización para tejer relaciones de diversa índole, ya sean laborales, sexo-afectivas, de amistad o de sororidad. El fútbol es mirado por ellas como un espacio de diversión (o "desmadre"), de contención psicológica, de desestrés o autocuidado. En concreto, presento la experiencia de mujeres que practican el fútbol en el municipio de Emiliano Zapata, en el estado de Morelos, que forma parte de la región sur.

El fútbol soccer, 1 bajo su forma reglamentada y atravesado por el proceso de deportivización ${ }^{2}$ del siglo XX, se ha extendido a nivel mundial, con una gran aceptación y participación social en América Latina, apoyado en gran medida por procesos mediáticos. (Galeano, 1995) Sin embargo, la presencia de juegos llevados a cabo con un objeto redondo (de diversos materiales) se ha documentado en distintas partes del mundo. En la región mesoamericana se han registrado diversos juegos con un objeto esférico.

En México, el juego de pelota (nauallachtli, ullamaliztlochaaj) se origina aproximadamente hace 3500 años, data de la cancha más antigua registrada hasta el momento en Chiapas, al sur del país. Existen versiones similares en la actual Sinaloa, zona norte de México (Aguilar, 2001) y entre los grupos mixtecos. El juego de pelota prehispánico fue un tipo de juego "ritual", cosmogónico, que simboliza la complementariedad de opuestos, como la vida y la muerte. Asimismo, recreaban aspectos del universo, en donde el uso y trayecto de la pelota representaba el viaje del sol. Son muy variadas las manifestaciones del juego, debido a su gran extensión, pero en ciertos casos la pelota era de caucho, pesando hasta 4 kilos y se le permitía pegarle con codos, cadera o glúteos. Se jugaba en lugares propios para esta actividad, formando parte de los espacios de control político e ideológico.

Las canchas del juego de pelota eran rectangulares, "constituidas normalmente por dos estructuras paralelas e inclinadas, paramentan un espacio horizontal central y longitudinal, que remata sus extremos por espacios transversales, para dar la forma de doble T, que le caracteriza" (Ocampo Hurtado, 2012, p.19). "Se creía que las canchas eran los portales o entradas al inframundo, los umbrales donde los hombres y los dioses interactuaban" (Aguilar, 2014, p. 76).

En Morelos, que es el Estado de la república donde se ubican las canchas y la liga de soccer femenil amateur, centro de este estudio, cuenta con un antiguo espacio de juego en Xochicalco (500-900 años d.C.), en la región suroeste del Estado, donde también se encuentran en la actualidad diversas canchas de fútbol.

\section{Los inicios del soccer y la participación de las mujeres}

El soccer, como hoy se le concibe, es considerado un deporte que surge en Inglaterra debido a documentos que atañen a su reglamentación. Sin embargo, Norbert Elias (1999) indica la existencia de registros de la época medieval, que se refieren a un balón pateado por personas de ambos géneros y de todas las edades, durante los carnavales. Hasta 1863, el fútbol se reglamenta como Football Association (Elias, 1999). La Federación Internacional de Football Asociación (FIFA), en su sitio virtual, menciona que el documento más antiguo encontrado hasta al momento es de dicha fecha, hallado en un bar de Londres, donde se redactan las primeras reglas del juego.

La práctica lúdica del soccer, al entrar al proceso de deportivización y, por ende, pasar por el filtro de la noción del "constructo" europeo, se reglamenta como deporte, dejando fuera la espontaneidad con la que se jugaba en los carnavales. Los inicios del soccer reglamentado por instituciones suponen la formación de una práctica asociada al cuerpo que excluye a las mujeres, constituyendo un mecanismo de construcción de la masculinidad hegemónica o patriarcal.

La información que aporta el sitio virtual de la Federación Internacional de Fútbol Asociación (FIFA), especifica que el primer mundial jugado por hombres fue en Uruguay, en 1930. Seis décadas después, mediante la lucha de las mujeres, en 1991 se lleva a cabo el primer campeonato de ellas en China. Formalmente, hay una distancia temporal de 61 años (Ramírez, 2018), aunque el primer encuentro no reconocido y boicoteado por 
la FIFA 3 fue en 1970. Fue un campeonato de fútbol femenil organizado por la Federación Europea de Fútbol femenil, donde participaron mujeres mexicanas e, inclusive, al año siguiente la sede fue México (Carreño, 2006).

El primer encuentro organizado por equipos a nivel nacional en México fue en 1922, considerado el primer antecedente de una liga profesional, jugada solo por hombres. En 1943, se consolida la liga de la primera división profesional varonil (Carreño, 2006). En el año 2016 se forma la primera liga femenil profesional. La profesionalización del soccer de hombres frente al de mujeres tiene una brecha temporal de 77 años en el país, a pesar de la popularidad de este deporte.

Asimismo, Archetti (1995) y Muñiz (2002) señalan que el deporte y, en concreto, el soccer, fue un elemento que acompañó la construcción del Estado-Nación y del "buen ciudadano" en América Latina. Archetti (1995) señala que para la formación y simbolización del Estado-nación argentino de fines del siglo XIX, se recurrió a imágenes o fotografías de futbolistas hombres, para representar la fuerza masculina y el "vigor" del Estado. Buscaban simbolizar mediante el cuerpo del hombre atlético, la idea de un Estado-nación creciente, en progreso, además de ir conformando una identidad nacional mediante el juego. Muñiz (2002) reporta una situación similar en México, en donde la sanidad, virilidad y fuerza del "cuerpo robusto" o "atlético", condensa la imagen del Estado-Nación en plenitud. $A$ inicios del siglo $X X$, se incorpora en las escuelas la noción de "educación física", siendo la gimnasia "el deporte ideal" para las mujeres, ${ }^{4}$ cuya utilidad era la salud de ellas para servir al cuidado de los otros.

Actualmente, sobre el fútbol recae en gran medida la parte emotiva-afectiva de la identidad nacional de muchos países. Es también un plano para representar y observar conflictos políticos, geográficos, religiosos, étnicos o económicos (Galeano, 1995). En México adquiere especial relevancia una final de fútbol de la copa de oro varonil entre la selección de Estados Unidos y la mexicana, en la medida que es una vía para "vencer", en el plano simbólico del juego, la desigualdad (económica y política, entre otras) que México tiene frente a su vecino del norte.
El juego posee una connotación lúdica, pero existen diversas formas de clasificar el juego. En el México prehispánico tenía un elemento de ritualidad (Ocampo, 2012); sin embargo, como señala Elías (1999), en el siglo XIX la industria se vuelve un eje rector de la vida socio-laboral, donde el "juego" y el deporte adquieren un sentido específico. Se reglamenta el tiempo bajo las nociones de "tiempo laboral" y de "ocio", siendo el deporte "no profesional/amateur", un elemento que organizará el tiempo de "ocio". Y, en específico, el fútbol soccer acompañará de manera central la vida fabril de los obreros a fines del siglo XIX y mediados del siglo XX.

\section{La liga, la futbolista y la futbolera}

La investigación, al desprenderse de la disciplina antropológica, tuvo un énfasis especial en la experiencia de vida de algunas mujeres participantes. Fueron trece futboleras quienes decidieron compartir lo que ha implicado el soccer en sus vidas: Zazú, Eva, Dane, Valeria, Fabi, Federica, Manola, Ana, Rocío, Laura, Azul, Hada y Martha. ${ }^{5}$ A partir de su mirada y de mis estancias en campo durante lapsos de los años 2013 y 2014, es que presento la información.

Las canchas y la liga en la cual participan las mujeres antes mencionadas se ubican en la región occidental del Estado de Morelos (colindante con el sur de la ciudad de México). Como sucedió a nivel mundial, en Morelos la industria tuvo una fuerte relación con el auge y promoción del soccer. Por las condiciones climatológicas y geográficas, gran parte del territorio morelense presenció la existencia de diversas fábricas destinadas a la obtención de azúcar. Desde el siglo XVI aparecen los primeros trapiches creados por el modelo económico colonial. Durante el periodo postcolonial o independentista, la industria cañera experimentó un auge bajo la visión del presidente Cárdenas (1934-1940), que nacionalizó la industria cañera. A la par, el soccer iba cobrando importancia como juego y forma de controlar el tiempo de "ocio" de los trabajadores, por lo que en esta zona se conformó en la década de 1960 un equipo que hasta la fecha tiene presencia y popularidad, "Los cañeros del Zacatepec", que llegó a jugar en primera división. 
En la década de 1990, de diversificación de la industria (textil, farmacéutica, automotriz, entre otras), que se asentó principalmente en Jiutepec, un municipio de la región occidental y otro en Cuautla, al oriente, han también abonado en la formación de equipos de soccer de mujeres, pues los modelos fabriles posteriores a la década de 1980, al dar paso de manera masiva a las mujeres en el sector obrero (Ariza y De Oliveira, 2004), propiciaron la conformación de equipos de fútbol.

En el municipio de Emiliano Zapata, donde se ubican las canchas de la liga femenil, existe una gran actividad futbolística diaria, que se intensifica los fines de semana, especialmente el domingo. Se han registrado alrededor de 35 canchas de soccer (con diferentes medidas y condiciones de las instalaciones y del pasto), según datos de los cancheros (dueños de canchas que las rentan a las ligas de fútbol) y de lo observado mediante google maps. Caminando por las calles, podemos observar a veces hasta tres canchas en una manzana.

Es de resaltar que el municipio se ve cruzado por diversos usos de suelo. Por un lado, han crecido las unidades habitacionales y se han trasladado dependencias estatales del sector salud y alimenticio por pertenecer al área conurbada de la capital, que se conforma de cuatro municipios (Cuernavaca, Jiutepec, Emiliano Zapata y Temixco). Asimismo, posee aún zonas de cultivo, principalmente de arroz y flores ornamentales. Actualmente, hay quienes han convertido sus tierras de sembradío en canchas de soccer, pues explican que es más rentable y no deben invertir en agroquímicos ni pesticidas; tampoco se preocupan por la calidad del agua de riego ni en dónde o a quién venderán lo cultivado.

Los relatos sobre el origen de la Liga de Zapata son escasos. Dentro de las narraciones recopiladas, sitúan la colonia Flores Magón de Cuernavaca como el punto donde comenzó la liga, hace aproximadamente 35 años, y cuya peculiaridad es que fue de las primeras zonas "industriales" de la capital morelense. Ahí se estableció la envasadora de refrescos "Coca Cola". Relata Ana, presidenta de la liga, que un señor de dicha colonia tenía una liga de varones y, al solicitar apoyo gubernamental para su liga, se le "ofreció", con la condición de crear un equipo de mujeres. Empezó a confor- marlo con apoyo de sus hijas y de su esposa. A la par, otro señor donó un terreno para que pudieran jugar los equipos. Se sumaron a la dirección dos mujeres que estudiaban biología en la universidad. Por fuentes orales, las primeras huellas de las futbolistas en el Estado se registran en colonias periféricas de Cuernavaca en las décadas de 1970 y 1980 . Eran maestras, trabajadoras del sector doméstico, empleadas en fábricas, con empleos asalariados o trabajadoras del gobierno.

La liga en la cual realicé el trabajo de campo es vista por las mujeres que gustan de jugar soccer, como una de las "más de antes" y "de las mejores" ligas del Estado, por el nivel futbolístico, de organización y participación de equipos. En el momento etnográfico, la liga registraba alrededor de 300 mujeres inscritas y contaba con 18 equipos, divididos en dos ramas, la premier o primera y la segunda división. Los partidos se llevaban a cabo los domingos en dos canchas contiguas, ubicadas dentro de un mismo predio, conocidas como las canchas de "Tamal verde y Tamal rojo". ${ }^{6} \mathrm{La}$ duración de los encuentros es de una hora.

La organización comprende diversos actores. La encabeza una presidenta quien se encarga, entre varias actividades, de registrar los equipos y a las jugadoras; de "hacer valer el reglamento", en casos de conflicto. Debe reservar las canchas para los partidos y recaudar las cuotas para posteriormente realizar los pagos que requiere la liga, como el de arbitraje y de cancha. Los equipos se organizan a su interior mediante la figura de la delegada o delegado, quien cumple diversas funciones "formales" y "no formales". La delegada/do es la encargada/o de un equipo. Algunas de sus funciones son: cobro del arbitraje a sus jugadoras (15 pesos aproximadamente), darle a las jugadoras playeras limpias para el partido, en ocasiones llevarles agua, bebidas rehidratantes o chicles y cloruro de etilo o hielos (en caso de recibir un golpe). Pueden realizar la alineación de las jugadoras para el partido y las tácticas o estrategias de juego a seguir. En ocasiones, la delegada también es jugadora de su propio equipo. A su vez, son quienes acuden a las reuniones de la liga para ajustar el reglamento o resolver problemas que se presenten y se encargan de tener listas las credenciales de las jugadoras. 
Las asistentes a la liga reflejan una gran heterogeneidad en edades, ocupaciones laborales, escolaridad, localidades de procedencia y estrato socioeconómico. Las edades comprenden desde los 9 a los 60 años, aunque la mayor parte posee entre 15 a 35 años. Las ocupaciones son diversas: participan profesoras, cuidadoras de quintas, jardineras, trabajadoras del hogar, taxistas, policías, profesionistas en diversas áreas (biólogas, contadoras, economistas, comunicadoras, enfermeras, entre otras), trabajadoras de limpieza, empleadas en fábricas o de mostrador, comerciantes, empleadas en labores de cocina y madres de familia. Debido al rango de edades, muchas de ellas son estudiantes de secundaria, preparatoria y universidad. La escolaridad también es heterogénea: hay quienes cuentan con primaria y algunas poseen el grado de doctorado. La mayor parte se ubica entre la secundaria y la preparatoria. Los ingresos mensuales pueden oscilar entre los 3,200 a los 30,000 pesos, o más. (De U\$170 a 1600).

Algunos de los equipos que actualmente juegan, se han originado desde el inicio de la liga, hace más de treinta años, como: Alacrancitas $^{7}$ de Puente de Ixtla, Águilas de Zapata, la Juventus y el México. (Figura 1).

Prevalece una situación de desigualdad en los partidos de ramas femeniles y varoniles. En el segundo caso, generalmente se les paga a los jugadores hombres un aproximado de 200 pesos o más, que puede significar el día de pago en una fábrica o en un trabajo asalariado. Las mujeres deben pagar 15 pesos (por uso de cancha y arbitraje). Los costos diferenciados de cancha y arbitraje entre ramas femeniles y varoniles, genera problemas para agendar los partidos.

Aparentemente, puede existir un beneficio, ya que son "más baratos" los encuentros de mujeres, lo que reduce gastos para la liga, pero los $\operatorname{cancheros}^{8} \mathrm{y}$ árbitros prefieren agendar partidos en rama varonil porque perciben una mayor paga. Un partido de mujeres se cobra alrededor de 130 pesos por cancha y 120 por arbitraje, mientras que el de hombres se cobra entre los 200 y 250 pesos por cancha y por arbitraje. Aunque uno de los cancheros refiere que la liga femenil es peleada entre ellos porque consumen más los productos $^{9}$ que venden al interior de las can- chas. Los hombres que juegan soccer suelen ir acompañados de su familia, y las esposas, madres o familiares acompañantes, llevan su propia comida y bebida.

Las mujeres de la liga de Zapata no suelen autodenominarse bajo categorías que refieran a una práctica deportiva, a pesar de que el fútbol tenga un lugar significativo en sus vidas. En las conversaciones sobre las experiencias vividas en el juego, se menciona el nombre del lugar donde está la liga, o bien se dice únicamente la liga. En ocasiones, refieren en diminutivo el lugar o el nombre de la liga para enfatizar la relación de afecto o cariño al ambiente vivido en el soccer. Poco se menciona el nombre de la cancha como lugar de referencia. El soccer se concibe como un espacio de organización social y no un lugar físico. La liga es metáfora de "ligar" o unir varias facetas de la vida, mediante las experiencias del fútbol. En esta organización social pueden encontrar trabajo, discutir sus problemas laborales o familiares y también formar relaciones afectivas e identitarias. Una participante encontró trabajo en la ayudantía del municipio, ya que ahí le informaron. Algunas jugadoras han conocido en la liga a su primera pareja afectiva-sexual. ${ }^{10}$

El ingreso a la liga se da por redes sociales; las amigas, vecinas o compañeras de escuela invitan a integrarse a las nuevas futboleras. No hay anuncios o forma de registrarse o inscribirse en un sitio, usualmente es por invitación.

Otro elemento central de autoidentificación, es el uso diferencial de los términos futbolista y futbolera. La futbolista se refiere a la profesionalización o institucionalización de la práctica deportiva. Cuando algunas de las chicas comentaron su deseo por haber querido formar parte de la selección mexicana de fútbol, indican "me hubiera gustado ser futbolista". Dos participantes de la liga expresan que tenían un gran deseo por vivir económicamente del soccer. Azul (entrevista en diciembre 2011), comenta: "me encanta jugarlo y qué mejor vivir de tu pasión". Cinco jugadoras concordaron en los siguientes impedimentos cruciales para ser futbolistas: ser mujeres," la falta de apoyo de sus padres y el no pertenecer a un estrato social de mayores ingresos económicos. ${ }^{12}$ 


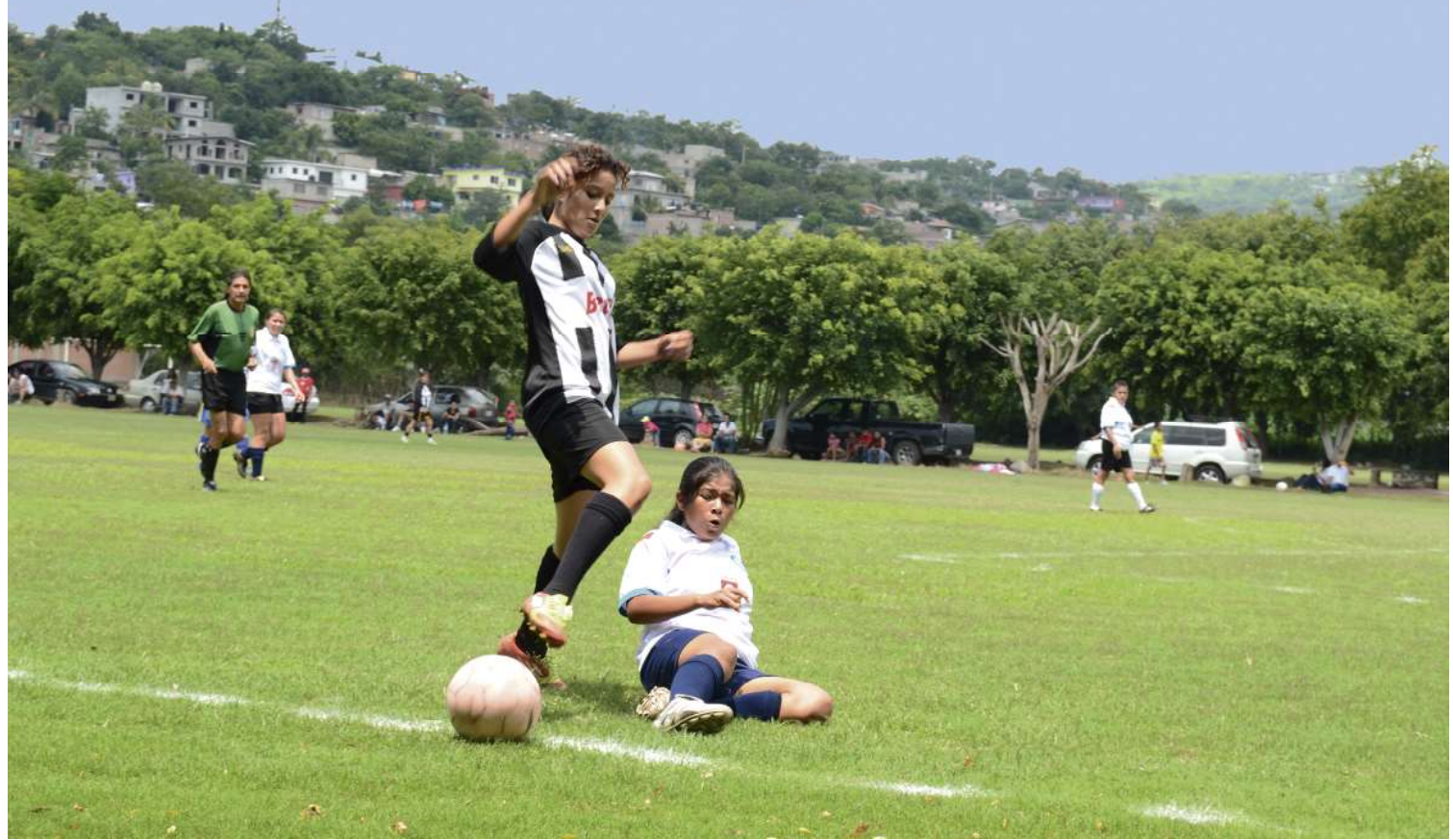

Figura 1. Liga de Zapata. Equipo de Juventus. Morelos, México. Foto Patricia Ramírez, octubre 2012

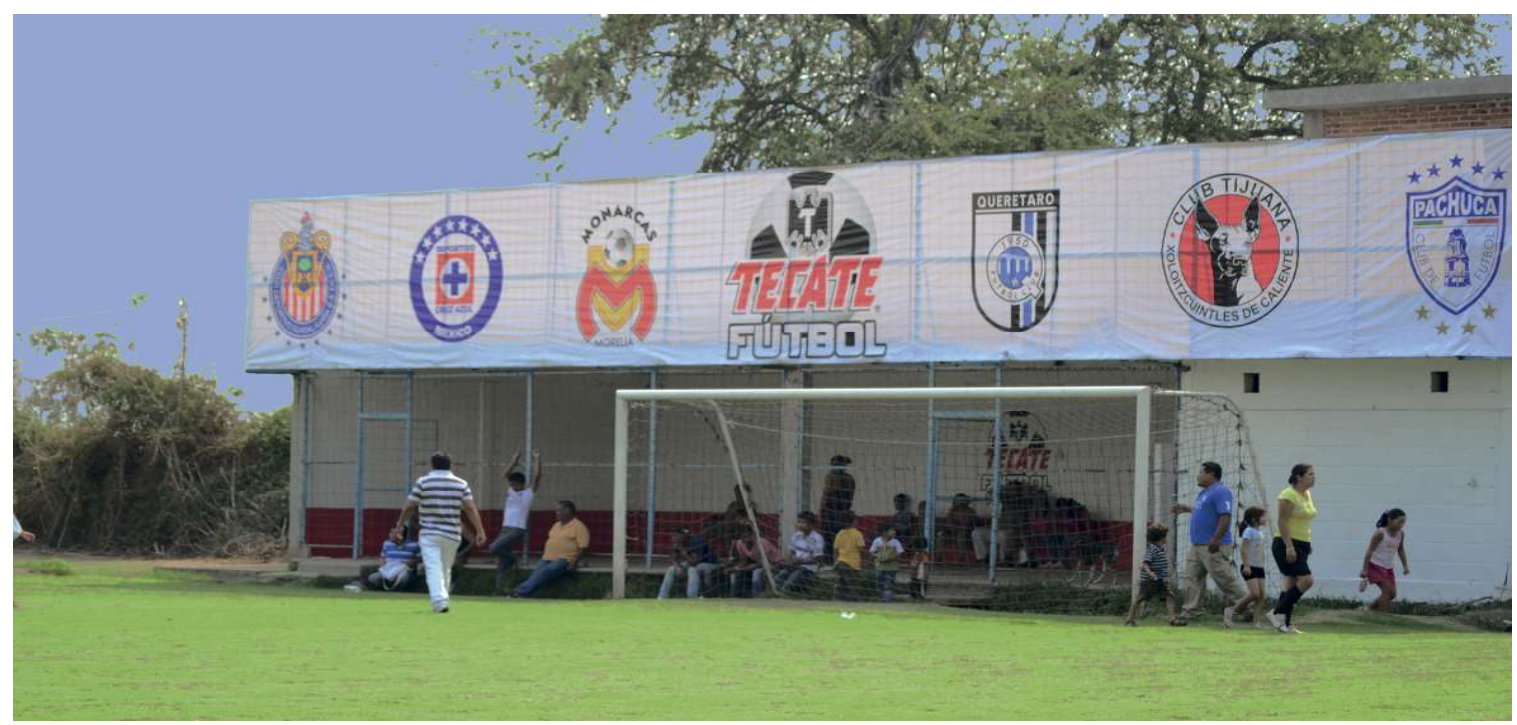

Figura 2. Barda del lado de la entrada (este), donde se ubican los baños y la tienda. Morelos. Foto Patricia Ramírez, 2013.

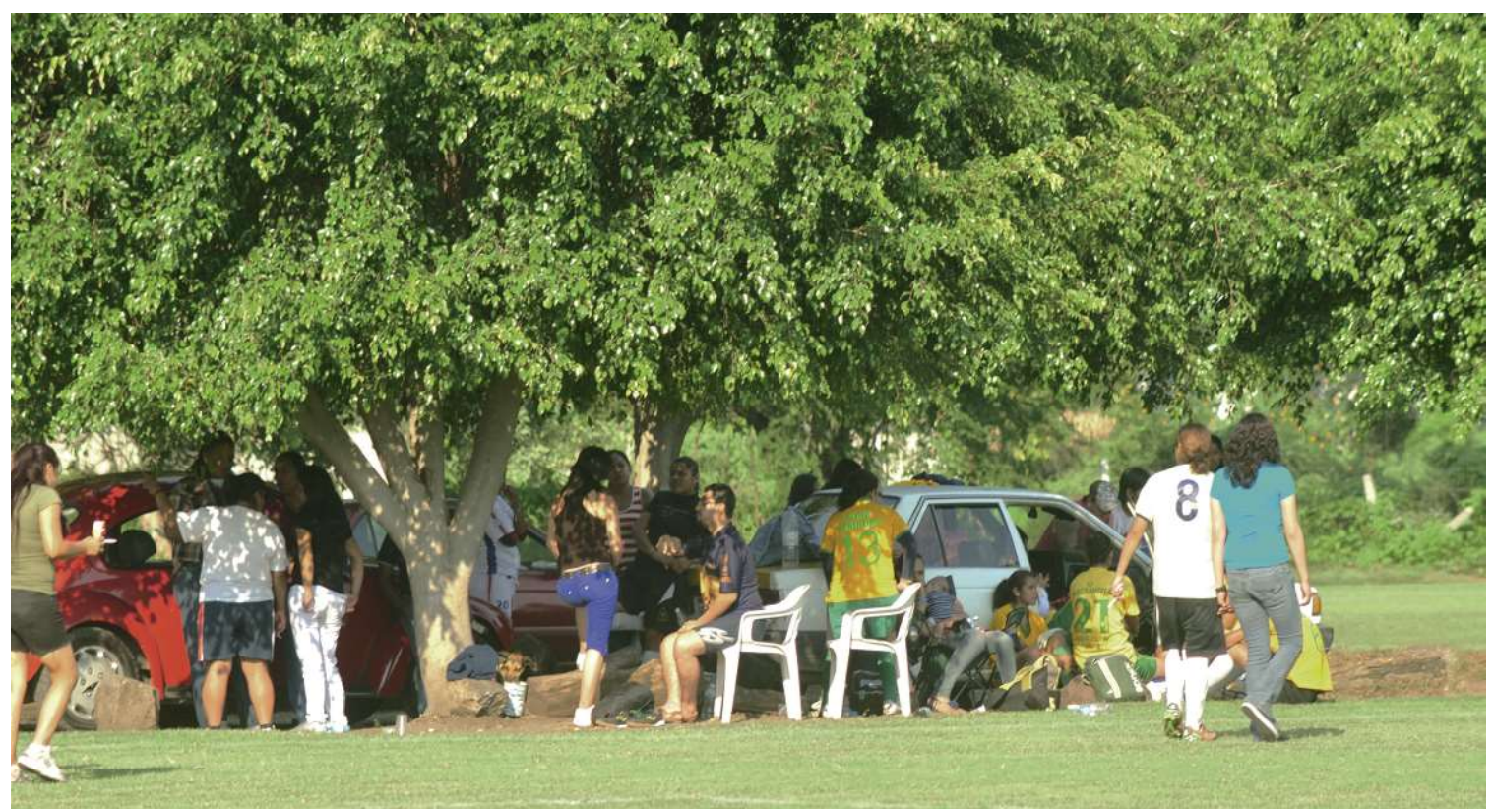

Figura 3. Vista del espacio deportivo y de la convivencia durante el juego. Morelos, México. Foto Patricia Ramírez, noviembre 2012 
La futbolera es quien gusta de ver, jugar y tener conocimientos sobre soccer o quien gusta de ir a presenciar partidos, ya sean o no de la liga. Por ello, la futbolera puede o no jugar soccer, pero si tener un "gusto" o "pasión" relacionado a esta práctica deportiva. Actualmente existe una posible aspiración de las mujeres por recibir un ingreso (no muy alto) del fútbol y formar parte de la vertiente profesional; si bien la liga no está centralizada en la capital del país, no en todos los estados existen equipos inscritos a la liga profesional.

La cancha se ubica en el municipio de Emiliano Zapata, sobre una calle de terracería. Está cercada y posee una entrada con reja por donde entran las personas y los coches. Por seguridad no se dejan los autos afuera. Las bardas de muchas canchas suelen estar pintadas de los colores y marcas de las cerveceras. Con el objetivo de hacerse publicidad y monopolizar la venta de su producto en una cancha, les pintan de forma gratuita las paredes, pero el canchero solo puede vender cerveza de la marca de quien le pintó la barda. Generalmente, las empresas que menos venden son las que hacen este tipo de "arreglos", pero puede traer problemas al dueño de la cancha porque la gente no le consume en su tienda y traen de otro lado las bebidas.

En este espacio se ubican dos canchas que no tienen las medidas reglamentarias, y son de menor tamaño. El terreno aproximadamente mide $700 \mathrm{~m} 2$. En la entrada del lado derecho se ubica la tienda y el baño. Del lado izquierdo, el estacionamiento. (Figura 2)

Los partidos se juegan los días domingo. Regularmente las jugadoras comienzan a llegar después del mediodía, ya que los partidos se agendan de esa hora en adelante. A veces, las jugadoras no son puntuales, generando problemas para completar el mínimo requerido de seis futbolistas por equipo, en una situación que puede frustrar a las que sí acuden.

Al término del primer partido agendado, la cancha se observa con más gente, más voces y risas. Conforme van avanzando los partidos, se van sumando las mujeres y los acompañantes, pues un buen porcentaje de quienes van terminando sus partidos se quedan a convivir. Cada equipo, al terminar su partido, se sienta a platicar, comer y/o beber en un espacio ya seleccionado. "Cada quien tienen su lugarcito", como refiere Yamileth (jugadora y delegada de un equipo). Especialmente, aquellos equipos que por el tiempo y la forma de cohesión han tejido fuertes lazos de convivencia. En este tipo de equipos suelen contar con la presencia de alguna o algunas mujeres con una suerte de carisma o liderazgo que unifica. Su liderazgo las lleva a organizar los convivios que se hacen después del partido; es decir, deciden a quién le toca llevar determinado platillo de comida o de bebida. Son además mujeres que constantemente, a través de sus pláticas y bromas, hacen reír al resto. Otro rasgo característico es que son mujeres mayores de 35 años de edad.

No todos los equipos poseen una cohesión que sobrepase a un convivio posterior al encuentro, pero, en estos casos, las futboleras que se quedan en la cancha buscan integrarse a otros grupos de convivencia, o bien se quedan sentadas viendo los partidos en un espacio que no sea el sitio habitual de algún equipo. Un factor presente en los equipos que se desintegran después del partido, es la conformación generacional homogénea; por ejemplo, entre los que predominan mujeres de una edad entre los 15 a los 20 años.

El estar un domingo en la cancha permite no solo platicar de los problemas cotidianos, sino representa un momento de descanso frente a la crianza. En el caso de las mujeres que juegan y tiene hijas o hijos y que acuden sin otro familiar que los cuiden mientras juegan, el grupo de amigas se encarga de compartir la crianza. En ciertos casos, a los niños menores de 3 años se les da de beber un trago de cerveza con el fin de que se "tranquilicen" un poco.

Asimismo, el poder jugar soccer es una lucha de negociación que se llega tener cuando las mujeres viven con alguna pareja que les impide acudir a la liga. Dos futboleras señalan que ellas les han explicado a sus esposos que deben ir por "motivos de salud", porque el jugar fútbol les ha aminorado o quitado dolores en la espalda y las piernas. En el caso de mujeres que tienen relaciones afectivas con mujeres, suelen jugar ambas, o bien no suele existir una estrategia de negociación constante para acudir a jugar.

Las canchas son también espacios para festejar los cumpleaños. Llevan comida y bebida 
que comparten entre sí. Las delegadas, por ejemplo, del equipo de la Juventus festejaron su cumpleaños llevando tostadas de pata puerco ${ }^{13}$ y refrescos. Sus amigas cooperaron y compraron las cervezas. El hecho de festejar eventos sociales, finalmente, es hacer del soccer un acompañante de momentos que son determinantes en la vida social e individual.

Yamilet, una de las jugadoras cuyo equipo lleva alrededor de siete años de formación y que ha conservado a la mayoría de sus integrantes, traza claramente la distribución del espacio entre los equipos. Cada equipo, indica, tiene una razón por la cual seleccionó determinado lugar para convivir después del partido. Yamilet seleccionó el suyo con sus amigas y jugadoras del equipo, porque hay un árbol que da sombra, está cerca de la tienda y de los baños $y$, a la vez, estaba alejado del desmadre de las chavas que son así. ${ }^{14}$ Ella explica que como trae a sus hijas, no le parece del todo conveniente que miren a las chicas besándose o tocándose el cuerpo. Señaló su preocupación, porque su hija (que oscila entre los 11 y 13 años) cuando acudía a la cancha, una amiga de su misma edad le decía que jugaran a besarse y agarrarse de la mano. (Figura 3)

Respecto a la trayectoria de las trece futboleras entrevistadas, se observa que la escuela y la familia son espacios de contención y regulación para practicar el soccer y, simultáneamente, transmiten un saber y una emotividad por jugar o ver jugar el fútbol. En el caso de la familia, las figuras masculinas coadyuvan en la construcción de un saber futbolístico. El padre y los hermanos hombres "enseñan" a jugar.

Desde mi experiencia de observación en la cancha de la liga y, por lo relatos de las futboleras, las mujeres no suelen enseñar a su hijas, hijos, hermanos o hermanas a jugar soccer. Solo dos delegadas enseñaban a sus hijas a jugar soccer y querían incorporarlas a sus respectivos equipos. Así mismo, durante el término de los encuentros o en el medio tiempo, cuando se desocupan las canchas, los padres hombres aprovechan para entrar, sobre todo con sus hijos varones, y se ponen a jugar. Aunque sí había niñas de 4 a 8 años que jugaban con otras niñas o niños de su misma edad. (Figura 4).
En el caso de la escuela, una política pública implementada en la década de 1990 (Carreño, 2006) obligó a incorporar a las mujeres al soccer en la clase de educación física, lo que impactó en la creación de equipos a nivel secundaria y en la aparición de los primeros torneos inter e intra escolares. No es gratuito que algunas de las mujeres que participaron conmigo en la investigación, señalaron tener el primer contacto con este deporte en la secundaria. Su relato no refiere a una edad sino el tiempo escolar de la secundaria, es decir, no señalan haber comenzado a jugar a los 14 o 15 años, sino aluden a un espacio socio-temporal (la escolarización).

Las mujeres que crecieron en estas dos corrientes, por un lado, aprenden a sentir emociones de goce o disfrute por jugar soccer $y$, por otro lado, la mamá, el papá o los compañeros de escuela les reprimían jugarlo y sentirlo a plenitud. Sus voces verbalizan la desigualdad, por no poderlo jugar en la magnitud que se le puede ofrecer a los hombres, aunque no por ello recrean historias de victimización.

A los 5 años es mi primer recuerdo en el kinder. Me apasiona desde que tengo uso de razón. No te puedo decir que es porque vi a alguien jugar o porque alguien me influenció. Me emocionó jugar y desde esa edad yo jugaba con hombres... (Zazú, comunicación personal, febrero 2013).

En el caso de Eva, siempre se ha recordado jugando fútbol con su papá y sus hermanos. Ella acudía con ellos a partidos en estadios profesionales de la CDMX y, cuando la querían castigar, le negaban hacer lo que a ella más le gustaba, que era jugar fútbol. Esta constante presión y vigilancia sobre el hecho de que ella pudiera practicar fútbol, en parte la obligó a dejar la universidad privada e irse a vivir con su actual pareja, a la cual conoce en una liga de fútbol femenil. Por su parte, su hermano, a pesar de ser mayor, vive en casa de sus padres y estudia una carrera.

Marta relata el ambiente familiar que teje el gusto y el saber por jugar fútbol. Este saber es además reconocido por su contexto social como un talento que le ha permitido vivir de este deporte.

Sí pues ellos (sus hermanos varones mayores) jugaban en un equipo todos los domingos, entonces pues yo me iba y me llevaban con ellos 
a jugar, entonces prácticamente mi infancia era de jugar con ellos y jugar fútbol, fútbol y fútbol. (Marta, comunicación personal, noviembre, 2012).

Para Dane, Ana, Fabi y Rosa, el encuentro con el soccer se relaciona con la secundaria. Durante los recreos en primaria, algunas de ellas cuentan haber jugado. La escuela era el único espacio para muchas de ellas, donde podían jugarlo. Aunque para Eva, Federica y Ana, la calle era el único espacio donde jugaban. "Yo siempre jugué con escuelas; o sea, la escuela nos jala a diferentes campos." (Dane, comunicación personal).

Muchas de ellas, al haberlo jugado desde edades tempranas, al ir a la primaria se encontraron de frente con la estructura patriarcal, ejercida por su grupo de compañeros en la escuela. Los niños varones si bien incorporaban a las mujeres a los juegos que conforman su "masculinidad", ejercían en ciertos momentos violencia hacia sus pares niñas. A veces las niñas jugaban, siempre y cuando, faltara un niño.

Me emocionó jugar y desde esa edad ( 5 años) yo jugaba con hombres porque solo había una compañera en el otro saloncito, de la misma edad, que le gustaba el fútbol, pero yo era más constante. Yo sí, diario, era mi religión jugar en cualquier ratito que se pudiera, o en el recreo, jugar fútbol. (Zazú, noviembre 2012). En tercero y cuarto de primaria jugué. En la canchota me ponía a jugar con los niños. Era la única mujer jugando con puros niños. Sí era divertido platicar con las niñas, pero después de un rato dices, no manches, quiero des-

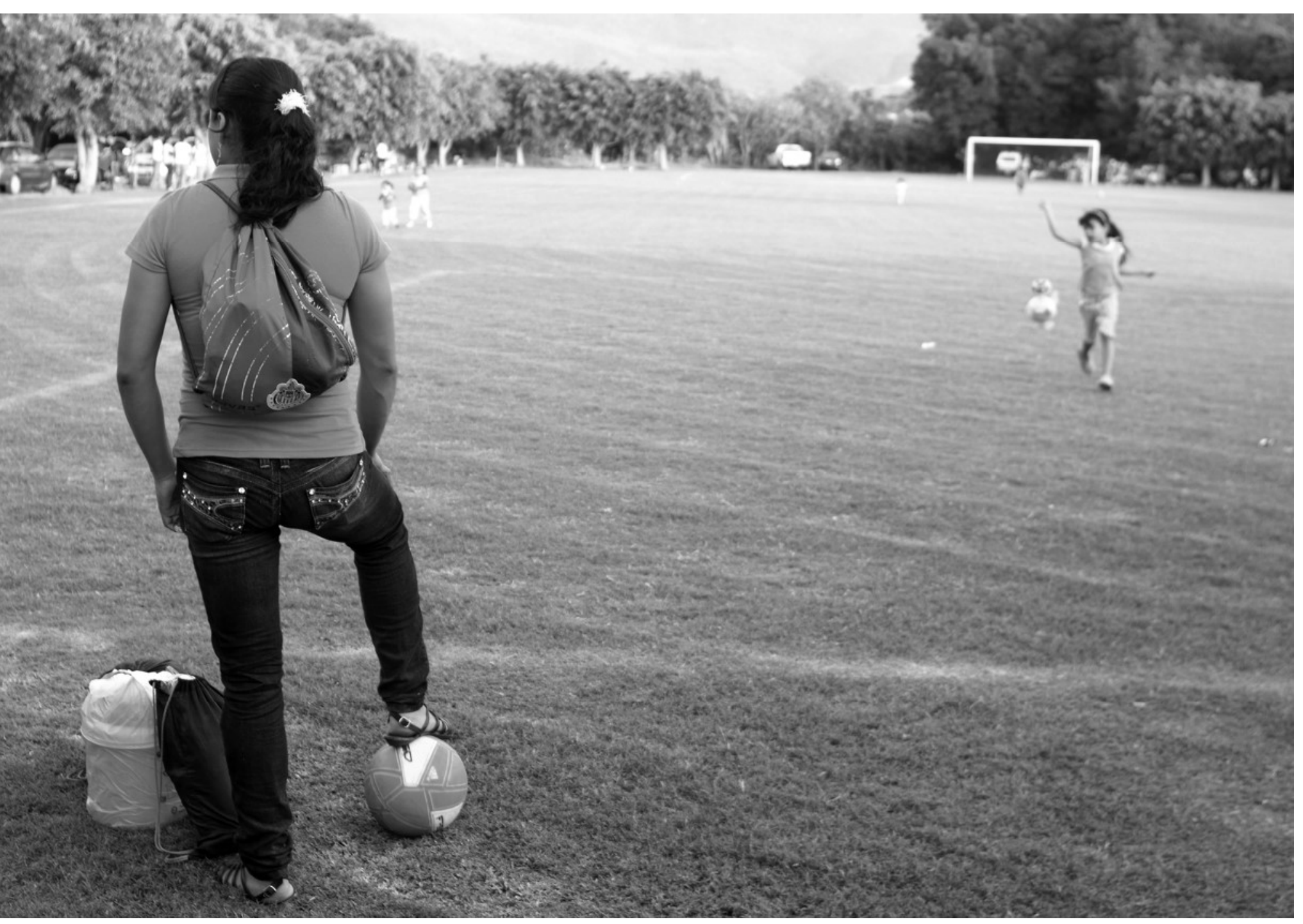

Figura 4. Canchas de fútbol. Morelos, México. Foto Patricia Ramírez, noviembre 2012 

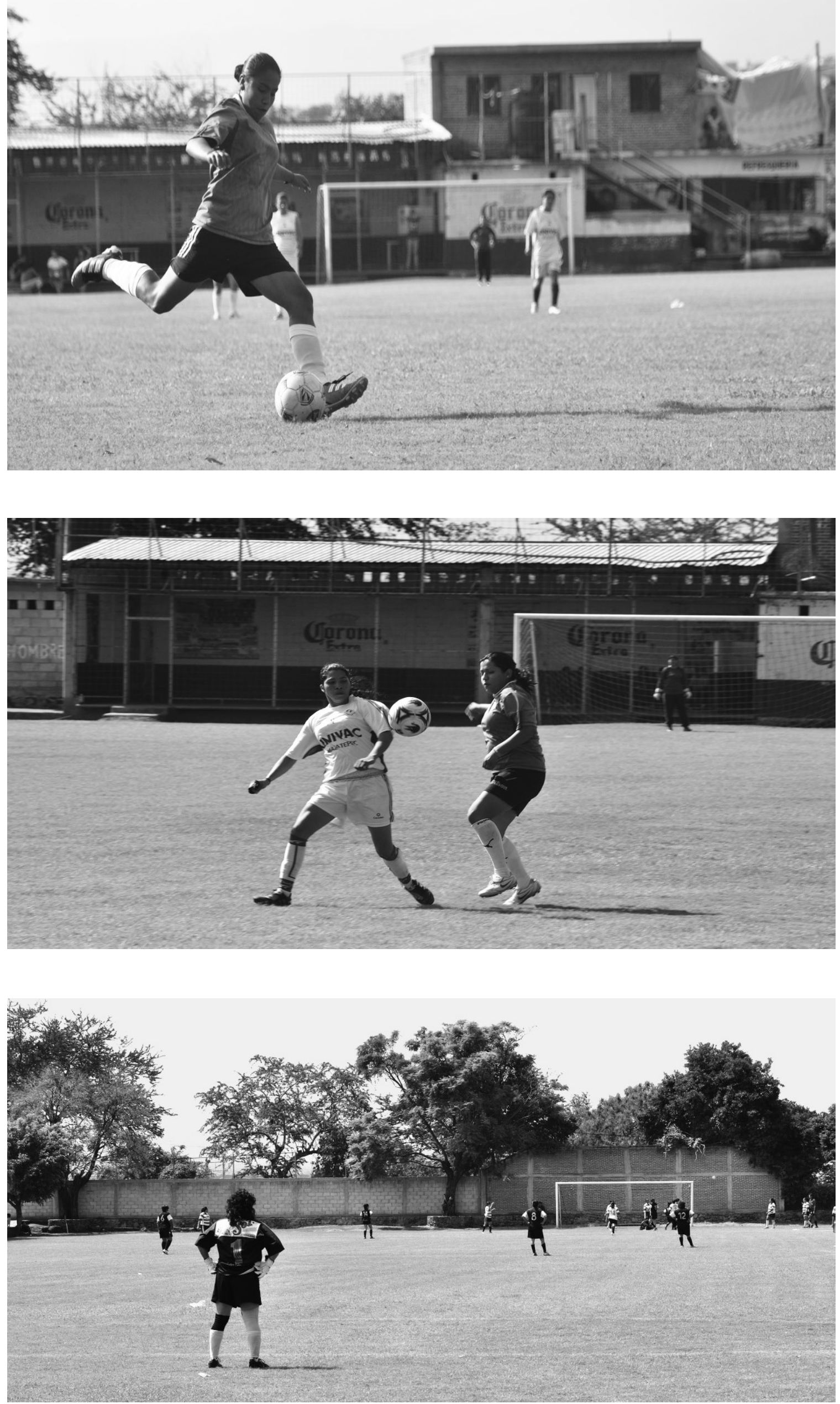

Figuras 5, 6 y 7. Partidos en la Liga de Zapata, Morelos, México. Fotos Patricia Ramíez. 2012 
entumirme y me iba a jugar. (Dane, febrero 2013).

El tiempo no ha resultado ser un factor de cambio. Entre Zazú y Dane hay alrededor de diez años de diferencia y sin embargo ambas expresan haber sido las únicas niñas de su escuela, jugando soccer.

Un factor que visibiliza el llegar a ser futbolera, es precisamente el valor para practicar el fútbol. (Figuras 5, 6 y 7) Para Manola, por ejemplo, le resultaba complicado exteriorizar que quería jugar soccer, por eso en la primaria, empezó a hacer atletismo "porque sí estaba permitido a las mujeres”. Más adelante, agrega:

Desafortunadamente una niña con tales habilidades y te lo digo ya como maestra ahorita, percibes perfectamente, una niña hiperactiva y con muchas capacidades físicas no es tonta, gracias a eso, y desafortunadamente me tuve que dar cuenta porqué es que no me dejaban jugar. De alguna manera, el escuchar comentarios que yo los analizaba y los concientizaba de que pues solamente lo decían porque no querían verme como niño cuando yo era una niña, y el miedo, el qué va a decir la gente. Lo que sí nunca me quitaron, es que yo dejara de jugar en la calle. Yo en la calle sí jugué. (Manola).

Tanto Manola como Federica en sus relatos refieren haber sentido presión social por jugar soccer, ya que en la calle les gritaban su nombre en masculino y les decían "machorras”. En el caso de Martha, por ejemplo, al ver que ella jugaba mejor que los niños, tanto ellos como sus padres le gritaban "que ya se fuera a la cocina, pinche machorra!"

\section{Reflexiones finales}

Los contextos sociales, en los que se construyen las experiencias de vida de las mujeres, se ven cruzados por relaciones de poder en contrasentido. Por un lado, en Latinoamérica y a nivel mundial, existe fuerte presencia y enorme popularidad del soccer. Como expresan las participantes de la Liga Zapata, el ser futbolera implica un gusto muy amplio y variado por el fútbol, desde verlo, practicarlo y poseer conocimientos; sin embargo, esta pasión se ve confrontada por la estructura patriarcal que ha hecho de la práctica del fútbol, un elemento para construir y delimitar la masculinidad hegemónica. El poder ver en un Estado de la república mexicana, sobre una región periférica del área conurbada de Morelos, canchas donde juegan mujeres, lleva tras de sí una larga lucha de ellas por poder jugarlo. La lucha ha ido avanzando en el plano deportivo, ya que actualmente existe la liga femenil profesional. Sin embargo, la lucha se ha acentuado más frente a la violencia social y política que vive todo el país y en especial Morelos, ${ }^{15}$ en donde ya solo el hecho de ser mujer es factor de peligro y resistencia.

\section{Notas}

1 Utilizo como sinónimos los términos fútbol y soccer para referirme al balompié bajo sus reglas actuales. Conformado por dos equipos de 11 jugadores cada uno, supervisados por cuatro árbitros, jugado con un balón en un área rectangular de pasto, con una portería a cada lado, donde se debe meter el balón en el arco contrario para obtener goles (o puntos). El lapso actual oficial es de 90 minutos con un intermedio de descanso de 15 minutos al medio tiempo.

2 Desde la antropología feminista, Fernando Huerta define el concepto como: "Un proceso ordenador de los cuerpos masculino-femeninos, en el mecanismo controlador de sus emociones, sentimientos, deseos, fantasías, imaginarios, manifestaciones y simbolizaciones de las subjetividades genéricas, en la cultura de la disciplina y supervisión de la salud corporal, en la práctica por excelencia y puesta en escena de los atributos de la masculinidad hegemónica." (2002, p. 49).

3 Entre varios aspectos de discriminación, no les permitían el uso de canchas oficiales. En el año 2004, ante la

búsqueda de Maribel Domínguez, futbolista mexicana, de poder jugar en la liga varonil de primera división de Europa, Joseph Blatter, presidente en aquel momento de la FIFA, declaró: "se debe mantener una clara división entre el fútbol masculino y el femenino". "No tenemos nada contra el hecho de que mujeres jueguen con hombres, pero no bajo la égida de la FIFA. Si esta señorita (Maribel Domínguez) quiere hacerlo, que lo haga. Pero no dentro de nuestra institución". (BBC, 2004).

4 “Las alumnas podrían ejercitarse todos los días en algunos movimientos gimnásticos sencillísimos, para los cuales no son necesarios aparatos costosos, complicados ni peligrosos y que, requiriendo brevísimo tiempo, son muy útiles para dilatar los pulmones, para aumentar la circulación, para poner en movimiento todos los músculos y articulaciones del cuerpo y para reforzar el organismo y prevenirlo contra el peligro de ser presa de alguna enfermedad grave. La mujer será así más útil a su familia y tendrá más probabilidades de hacer la felicidad propia y de los que la rodean”. Fragmento de un 
artículo publicado en 1923, en el número 4 de la Revista de Educación Física de México, (citado en Muñiz, 2002, p. 116).

5 Por motivos del anonimato solicitado por algunas de ellas, todos sus nombres fueron cambiados, debido a que se abordaban temas sobre la subjetividad de su sexuar.

6 Es una comida elaborada a partir de masa de maíz, en forma rectangular o cilíndrica. En el centro se coloca un poco de carne, o bien pescado, verduras o legumbres (depende de la región) y se bañan en salsas picantes. Se cubren con hojas secas de maíz o de plátano; depende también del lugar o país, pues al ser una comida de origen mesoamericano, se encuentra en varios países de Latinoamérica. Por el color de la salsa es que se refieren a los tamales como verde o rojo. En México también adquiere una connotación sexual, aludiendo al órgano sexual de las mujeres, por lo que entre las jugadoras causaba un poco de risa el nombre.

7 Da un sentido especial de identidad, ya que particularmente en el Estado de Morelos habita una de las especies más venenosas de este insecto por el clima seco y caluroso.

8 Es el dueño y/o encargado de la cancha. Recibe un ingreso por rentar sus canchas de soccer y puede ofertar otros servicios, como venta de cervezas, alimentos, bebidas, servicio de baño y estacionamiento.

9 Para algunos cancheros las mujeres consumen más cerveza, ya sea sola o preparada con salsas picantes, por lo que consideran que reciben un mayor ingreso. Algunas

\section{Referencias bibliográficas}

Aguilar, M. (2001). Ulama. El juego de pelota prehispánico que sobrevivió hasta nuestros días. Arqueología Mexicana, (152), 73-79.

Archetti, P. E. (1995). Estilo y virtudes masculinas en el Gráfico: La creación del imaginario del fútbol argentino. Desarrollo Económico - Revista de Ciencias Sociales, 35(139), 419-442.

Ariza, M. y De Oliveiera, O. (2004). Universo familiar y procesos demográficos. Imágenes de la familia en el cambio de siglo. Ciudad de México, México: UNAM.

British Broadcasting Corporation (BBC) (2004). La FIFA le dijo "no" a Marigol. Recuperado de http://news.bbc.co.uk/hi/spanish/misc/newsid_4110000/4110065.stm

Carreño, M. (2006). Fútbol Femenil en México 1969-1971 (Tesis Licenciatura), Universidad Nacional Autónoma de México, Ciudad de México, México.

Díaz, G. (2019). Pese a cuatro años de alerta de género en Morelos, los feminicidios van al alza, alertan. Revista Proceso Recuperado de https://www.proceso.com. mujeres también refirieron que les gusta tomar en la cancha porque sienten que es un lugar seguro, a diferencia de un bar.

10 Seis de las trece jugadoras entrevistadas, refieren haber conocido en la liga a la primera mujer con quien formaron una relación afectivo-sexual.

11 El momento etnográfico, cuando realicé el trabajo de campo, fue previo a la creación de la liga mexicana femenil de fútbol profesional (Liga MX femenil) formada en 2016 por la lucha de las mujeres.

12 Previo al 2016, la única vía para percibir ingresos de soccer era pertenecer a la selección femenil de México, pero dos jugadoras de la liga me comentaron que para ingresar se debía dar un monto económico que no era fácil de reunir.

13 Debido a que "echar pata" es un sinónimo de tener relaciones sexuales, durante la socialización este elemento se utilizó para generar el "albur" o bromas de contenido sexual.

14 El desmadre tiene diversas connotaciones, en general es un sinónimo de "diversión", pero es una diversión cruzada por bromas, humor, albures, situaciones o comentarios sexuales, emborracharse o inclusive drogarse. El desmadre es salir de una pauta de comportamiento, socialmente vista como "correcta". Y el así es un concepto local que puede leerse como un término "políticamente correcto", o bien una forma de "no nombrar" a las mujeres que tienen prácticas y/o relaciones sexuales con otras mujeres.

15 Mil feminicidios denunciados ante las autoridades judiciales del 2000 al 2019 (Díaz, 2019).

mx/598540/pese-a-cuatro-anos-de-alerta-de-generoen-morelos-los-feminicidios-van-al-alza-alertan

Elías, N. y Dunning, E. (1995). Deportes y ocio en el proceso de la civilización. Ciudad de México, México: Fondo de Cultura Económica.

Federación Internacional de Football Asociación (FIFA) (2019), Recuperado de https://es.fifa.com/about-fifa/who-we-are/the-laws/

Galeano, E. (1995). El futbol a sol y sombra. Buenos Aires, Argentina: Siglo XXI Editores.

Huerta, F. (2002). La deportivización del cuerpo masculino. El cotidiano. Vol 18, $n^{\circ} 113$, México DF., 47-57.

Muñiz, E. (2002). Cuerpo, representación y poder. México en los albores de la reconstrucción nacional, 19201934. Ciudad de México, México: Primera-UAM (Azcapotzalco)-Porrúa.

Ocampo, J. (2012). El juego de pelota prehispánico y los juegos olímpicos. Revista U.D.C.A Actualidad \& Divulgación Científica, (15) 17-25.

Ramírez T. (2018). Futboleras de Morelos. El sol de Cuernavaca, 31-33. 